\title{
Factors Associated with Virological Non- suppression among HIV-Positive Patients on Antiretroviral Therapy in Uganda, August 2014-July 2015
}

Lilian Bulage ${ }^{1,2^{*}}$, Isaac Ssewanyana ${ }^{2}$, Victoria Nankabirwa ${ }^{3}$, Fred Nsubuga ${ }^{1}$, Christine Kihembo ${ }^{1}$, Gerald Pande ${ }^{1}$, Alex R. Ario ${ }^{1}$, Joseph KB Matovu ${ }^{1,3}$, Rhoda K. Wanyenze ${ }^{1,3}$ and Charles Kiyaga ${ }^{2}$

\begin{abstract}
Background: Despite the growing number of people on antiretroviral therapy (ART), there is limited information about virological non-suppression and its determinants among HIV-positive (HIV+) individuals enrolled in HIV care in many resource-limited settings. We estimated the proportion of virologically non-suppressed patients, and identified the factors associated with virological non-suppression.
\end{abstract}

Methods: We conducted a descriptive cross-sectional study using routinely collected program data from viral load $(\mathrm{VL})$ samples collected across the country for testing at the Central Public Health Laboratories (CPHL) in Uganda. Data were generated between August 2014 and July 2015. We extracted data on socio-demographic, clinical and $V L$ testing results. We defined virological non-suppression as having $\geq 1000$ copies of viral RNA/ml of blood for plasma or $\geq 5000$ copies of viral RNA/ml of blood for dry blood spots. We used logistic regression to identify factors associated with virological non-suppression.

Results: The study was composed of 100,678 patients; of these, 94,766(94\%) were for routine monitoring, 3492(4\%) were suspected treatment failures while 1436(1\%) were repeat testers after suspected failure. The overall proportion of non-suppression was $11 \%$. Patients on routine monitoring registered the lowest (10\%) proportion of nonsuppressed patients. Virological non-suppression was higher among suspected treatment failures (29\%) and repeat testers after suspected failure (50\%). Repeat testers after suspected failure were six times more likely to have virological non-suppression $\left(\mathrm{OR}_{\mathrm{adj}}=6.3,95 \% \mathrm{Cl}=5.5-7.2\right)$ when compared with suspected treatment failures $\left(\mathrm{OR}_{\mathrm{adj}}=3.3,95 \% \mathrm{Cl}=3.0-3.6\right)$. The odds of virological non-suppression decreased with increasing age, with children aged $0-4$ years $\left(\mathrm{OR}_{\mathrm{adj}}=5.3,95 \% \mathrm{Cl}=4.6-6.1\right)$ and young adolescents $\left(\mathrm{OR}_{\mathrm{adj}}=4.1,95 \% \mathrm{Cl}=3.7-4.6\right)$ registering the highest odds. Poor adherence $\left(\mathrm{OR}_{\mathrm{adj}}=3.4,95 \% \mathrm{Cl}=2.9-3.9\right)$ and having active $\mathrm{TB}\left(\mathrm{OR}_{\mathrm{adj}}=1.9,95 \% \mathrm{Cl}=1.6-2.4\right)$ increased the odds of virological non-suppression. However, being on second/third line regimens $\left(\mathrm{OR}_{\mathrm{adj}}=0.86\right.$, $95 \% \mathrm{Cl}=0.78-0.95)$ protected patients against virological non-suppression.

Conclusion: Young age, poor adherence and having active TB increased the odds of virological non-suppression while second/third line ART regimens were protective against non-suppression. We recommend close follow up and intensified targeted adherence support for repeat testers after suspected failure, children and adolescents.

Keywords: Antiretroviral therapy, Virological non-suppression, Uganda

\footnotetext{
* Correspondence: Ibulage@musph.ac.ug; lilian.bulage@gmail.com

${ }^{1}$ Uganda Public Health Fellowship Program - Field Epidemiology Track, Kampala, Uganda

${ }^{2}$ Central Public Health Laboratories, Ministry of Health, Kampala, Uganda

Full list of author information is available at the end of the article
}

\section{Ciomed Central}

(c) The Author(s). 2017 Open Access This article is distributed under the terms of the Creative Commons Attribution 4.0 International License (http://creativecommons.org/licenses/by/4.0/), which permits unrestricted use, distribution, and reproduction in any medium, provided you give appropriate credit to the original author(s) and the source, provide a link to the Creative Commons license, and indicate if changes were made. The Creative Commons Public Domain Dedication waiver (http://creativecommons.org/publicdomain/zero/1.0/) applies to the data made available in this article, unless otherwise stated. 


\section{Background}

The number of people accessing antiretroviral therapy (ART) has gradually increased in the recent years [1]. With the rising numbers of patients accessing ART, it is important to sustain treatment success and limit development of treatment failure. To allow timely detection of treatment failures, WHO in July 2013 recommended use of viral load testing as the gold standard to monitor patients response to ART [2]. Establishment of the virological suppression status among patients enrolled on ART is important for timely detection of treatment failures, identification of patients in need of more intensive adherence support and minimizes development of drug resistance and unnecessary switch to expensive and limited ART regimen options [3, 4].

The Ugandan guidelines recommend that viral load testing should be done 6 months after initiating ART and thereafter annually for people who have achieved viral suppression. However, people with detectable viral loads undergo targeted intensified adherence support for 6 months followed by confirmatory viral load testing in order to differentiate poor adherence from treatment failure. Those with treatment failure as defined by two detectable viral load measurements above the threshold are switched to second-line ART [2].

Previous studies have highlighted a number of factors that may be associated with virological suppression. Patients with WHO clinical staging 4 are more likely to be non-suppressed while those whose health status is evaluated by physicians on each clinic visit are less likely to experience virological failure [5]. Children and adolescents on ART are more likely to have high viral loads [6]. Suboptimal adherence, poor tolerability, and drug and food interactions, CD4 cell count, treatment history and drug-resistance (primary or transmitted) have also been associated with virological non-suppression. Suboptimal adherence and drug intolerance are the major cause of regimen discontinuations and hence virological failure [7-9]. Virological non-suppression may also be caused by patient-related factors such as co-morbidities, incomplete medication adherence and missed clinic appointment and interruption of or intermittent access to ART, and ARV regimen related factors such as drug adverse effects, suboptimal pharmacokinetics, suboptimal virological potency and food requirements, amongst other factors [10].

In 2014 the Joint United Nations Programme on HIV/ AIDS (UNAIDS) set new targets towards elimination of HIV, including diagnosis of $90 \%$ of HIV infected individuals, access to treatment for $90 \%$ of identified HIV infected persons, and 90\% viral suppression among those initiated on treatment [11]. These targets have since been adopted by several countries including Uganda. Thus, viral load is a critical indicator for HIV treatment quality and tracking of progress towards national and global indicators.

Despite the increasing number of HIV+ patients accessing ART [1], there is limited information about nonsuppression rates amongst the different groups of people enrolled in care in Uganda and many resource limited settings in general. Studies that have highlighted the factors associated with virological suppression in most developed countries and resource limited settings have used lower cut-offs to determine non-suppression. The thresholds used range from 300 to 500 copies $/ \mathrm{ml}$ of blood [12]. However, since several clinical and epidemiological studies have highlighted the risk of HIV transmission being very low when the viral load is lower than 1000 copies/ml, WHO recommends using 1000 copies/ $\mathrm{ml}$ as the threshold when using plasma and 5000 copies/ $\mathrm{ml}$ for dry blood spots (DBS) [2, 13]. Uganda and other countries such as Swaziland are using the WHO recommended thresholds. Most Ugandan studies that have assessed viral suppression have been based on small numbers $[14,15]$. Finally, the relative contribution of the factors leading to virological non-suppression may vary across settings and population groups and context specific data are critical to the implementation of corrective measures. The aim of this study was to estimate the proportion of virologically non-suppressed HIV+ patients who had been on ART for at least 6 months and identify factors associated with virological non-suppression using a large national dataset of routinely collected program data at the Central Public Health Laboratories (CPHL) in Uganda between August 2014 and July 2015.

\section{Methods}

Study design

This was a descriptive cross-sectional study using a large national dataset of routinely collected program data (sample size 100,678) that were submitted to the Central Public Health Laboratories (CPHL) from all health facilities in Uganda between August 2014 and July 2015.

\section{Study setting}

The study was conducted at CPHL where the centralized VL testing is done in Uganda. Centralized monitoring of response to ART using viral load as a gold standard started in August 2014. The samples come from all over the country from both private and government health facilities offering HIV ART services. Uganda is located within the East African region with a population of 34.9 million [16] and a general HIV prevalence of 7.3\% [17]. According to the 2014 Uganda HIV and AIDS Country Progress Report, 1,500,000 people were living with HIV in 2014 [18]. Of these, 750,896 (50\% coverage) were active on ART by Dec 2014 [18]. There were 125,705 new active patients on ART by end of 2014 [18]. According 
to the viral load testing request form version for Uganda, the three main reasons for viral load testing are: 1) routine testing; 2) suspected failure, and 3) repeat viral load testing after suspected treatment failure for patients who were virologically non-suppressed on first time testing and underwent enhanced adherence support for 6 months and submitted a follow-up sample at the end of 6 months.

\section{Study participants and data collection}

We used VL testing data for samples corresponding to HIV positive patients who had been on ART for at least 6 months. Data generated from the start of VL testing at CPHL in August 2014 to July 2015 were considered for the study.

\section{Measures}

The primary outcome was virological non-suppression, defined as having $\geq 1000$ copies of viral RNA/ml of blood for plasma or $\geq 5000$ copies of viral RNA $/ \mathrm{ml}$ of blood for dry blood spots [19]. We abstracted data on viral load testing results (for plasma and DBS) measured in terms of viral RNA copies/ml of blood, age, sex, duration of treatment, treatment line (first, second, third), identification for treatment initiation at baseline (ePMTCT option $\mathrm{B}+$, child under $15, \mathrm{CD} 4<500$ and TB infection), pregnancy status, breast feeding status, having active TB, health facility level, reasons for viral load testing (routine monitoring, suspected treatment failure, and repeat VL test after suspected treatment failure [for patients who were not suppressed on first time testing underwent enhanced adherence support for six months and submitted a follow up at the end of the six months]).

\section{Data analysis}

We analyzed the entire study data set to estimate the proportion of patients with virological non-suppression, and to identify factors associated with virological nonsuppression. In-addition, we conducted sub-group analyses in line with the 3 major reasons for viral load testing in Uganda (routine monitoring of response to treatment, suspected treatment failure, and repeat viral load testing after suspected failure). We used univariate analysis to establish the socio-demographic and clinical characteristics of the study population, the overall and group specific proportions of patients with virological non-suppression. Virological non-suppression proportion was defined as the percentage of the number of total not suppressed among the total number tested. The proportion with viorological non-suppression were further evaluated by age group, gender, duration on treatment, reported adherence levels, pregnancy status, breast feeding status, having active $\mathrm{TB}$, treatment line, reason for VL test (routine monitoring, suspected treatment failure, and repeat VL test after suspected failure) and health facility level.

We created the outcome variable of suppression status by categorizing the viral load results into two groups. All results $<1000$ or 5000 copies $/ \mathrm{ml}$ of blood for plasma and DBS respectively were categorized as suppressed while $\geq 1000$ or 5000 copies/ml of blood for plasma and DBS respectively were categorized as not suppressed. At the exploratory analysis stage, we realized that the percentage of variables with missing values was $<10 \%$ of all the variables in the data set. Missing values were dropped automatically from each variable and analysis was conducted based on the totals with complete records.

We used bivariate analysis to determine strengths of association between the independent variables and the outcome variable (virological suppression status). Crude odds ratios (OR) and 95\% confidence intervals were calculated. We used multivariate logistic regression to identify factors independently associated with virological non- suppression. Adjusted odds ratios (OR) and 95\% confidence intervals were calculated. We considered the reason for viral load testing (routine monitoring, suspected treatment failures, and repeat testers after suspected treatment failure) in Uganda as the main exposure variable of interest. We adjusted for age, sex, ARV adherence, treatment line (first, second/third), identification for treatment initiation at baseline (ePMTCT option $\mathrm{B}+$, child under 15, CD $4<500$ and TB infection), having active $\mathrm{TB}$, duration on treatment, and health facility level. We dropped the option "other" under the option for indication for treatment initiation at baseline when conducting bivariate and multivariate analysis. This was due to the fact that it was not clear which categories of patients were categorized as "other". In the sub-analyses, age group was considered to be the main exposure variable of interest. In addition, factors were entered into logistic regression models based on biological plausibility, previous literature, and statistical significance in bivariate analysis. We tested for interaction and did not find any statistically significant interaction terms to report on. Pregnant and breast feeding status were excluded from model building because they only apply to females. Statistical significance was considered at $p$-value $<0.05$ (two-sided). Data were entered into Excel 2007 and analyzed using Epi-info version 7.

\section{Ethical consideration}

We used program data collected for routine patient care at all health facilities in Uganda and submitted to the Central Public Health Laboratories (CPHL) which is mandated to conduct centralized viral load testing in Uganda. All data did not carry personal identifiers. The data were not accessible by any other third parties other than the study team. Permission to use the data was 
sought from the Ugandan Ministry of Health under whose mandate CPHL falls.

\section{Results}

\section{Patients' characteristics}

Table 1 shows the characteristics of the 100,678 patients whose viral load data were available for analysis. Of these, 94,766 (94\%) were for routine monitoring, 3492 (4\%) were for suspected treatment failures while 1436 (1\%) were for repeat testers after suspected failure. In general, females contributed the biggest proportion of the study sample, ranging from 55 to $68 \%$ across the three patient-subcategories. Most of the patients were aged $35+$ years: $53,489(56 \%)$ among patients for routine monitoring, 2140 (61\%) among suspected treatment failures and 430(30\%) among repeat testers after suspected failure. Majority of the patients had been initiated on ART basing on their CD4 < 500, i.e., 70,116 (76\%) among patients for routine monitoring, 2832 (85\%) among suspected treatment failures and 839 (62\%) among repeat testers after suspected failure. All the 3 categories had majority of the patients on first line regimens, i.e., routine monitoring 89,382 (95\%), suspected treatment failures $3177(92 \%)$ and repeat testers after suspected failure 1070 (75\%). Reported adherence (>95\%) was highest among patients for routine monitoring 81,478 (89\%), followed by repeat testers after suspected failure 1005 (74\%), and lowest among suspected treatment failures 2278 (68\%). The proportion of women who were either pregnant or breast feeding ranged from 1 to $5 \%$ across all the 3 patient categories. Patients with active TB represented only $1-5 \%$ of the study sample across all the patient categories.

\section{Proportion of patients with virological non-suppression}

Table 2 shows the proportion of patients with overall virological non-suppression and by the three patient subcategories. The overall proportion of virologically nonsuppressed patients in the study sample was $11 \%$. In general, repeat testers after suspected failure had the highest proportion of patients with virological non-suppression (50\%), followed by suspected treatment failures $(29 \%)$ and least routine monitoring patients (10\%). In-addition, the proportion of virologically non-suppressed patients were highest among the repeat testers after suspected failure, followed by suspected treatment failures and lastly patients for routine monitoring considering all the variables explored.

In general, the proportion of virologically nonsuppressed patients decreased with increasing age, with the highest proportion being $29 \%$ for children aged 0 4 years, followed by $27 \%$ for adolescents aged $15-$ 19 years and least $7 \%$ for adults aged $35+$ years. The same trend is observed across the 3 patient sub- categories. Males (13\%) had a slightly higher proportion of non-suppressed patients compared the females (10\%). Breast feeding $(6 \%)$ and pregnant $(8 \%)$ mothers had the lowest proportion of virologically non-suppressed patients amongst all the different patient categories explored. In general, virological non-suppression was highest amongst patients with reported adherence levels of $<85 \%$ (35\%) followed by patients with $85-94 \%$ $(17 \%)$ and least among those with adherence levels $>95 \%$ (10\%). Regional and National referral hospitals had the highest proportion of virologically nonsuppressed patients (12\%), followed by specialized HIV care services with $11 \%$, and least health centre IV and general hospitals, and health centre II and III each with $9 \%$ (Table 2).

\section{Factors associated with virological non-suppression}

Table 3 shows the crude and adjusted odds ratios associated with virological non-suppression by reason for viral load testing and other background characteristics. At bivariate analysis level, the reason for viral load testing was significantly associated with virological non-suppression: Suspected treatment failures $\left(\mathrm{OR}_{\text {crude }}=4.2,95 \% \mathrm{CI}=3.6-\right.$ $4.2)$ and repeat testers after suspected failure $\left(\mathrm{OR}_{\text {crude }}=9.5\right.$, $95 \% \mathrm{CI}=8.6-10$ ) were more likely to be virologically nonsuppressed, compared with routine testers. In addition, young age was significantly associated with virological non-suppression: Children aged 0-4 years $\left(\mathrm{OR}_{\text {crude }}=5.1\right.$, $95 \% \mathrm{CI}=4.6-5.7)$ and adolescents aged 15-19 years $\left(\mathrm{OR}_{\text {crude }}=4.7,95 \% \mathrm{CI}=4.4 .4-5.2\right)$ were more likely to be virologically non-suppressed compared with patients aged $35+$ years. Patients with reported adherence level $<85 \%$ $\left(\mathrm{OR}_{\text {crude }}=5.1,95 \% \mathrm{CI}=4.6 .4-5.8\right)$ were also more likely to be virologically non-suppressed compared to patients with $>95 \%$ adherence level. Similarly, patients on second/ third line treatment $\left(\mathrm{OR}_{\text {crude }}=1.3,95 \% \mathrm{CI}=1.3 .4-1.4\right)$, patients with active $\mathrm{TB}\left(\mathrm{OR}_{\text {crude }}=2.1,95 \% \mathrm{CI}=1.7-2.5\right)$ were also more likely to be virologically non-suppressed. Pregnancy $\left(\mathrm{OR}_{\text {crude }}=0.77,95 \% \mathrm{CI}=0.65-0.91\right)$ and breast feeding $\left(\mathrm{OR}_{\text {crude }}=0.61,95 \% \mathrm{CI}=0.54-0.69\right)$ were protective against virological non-suppression (Table 3).

At multivariate analysis level, being a suspected treatment failure $\left(\mathrm{OR}_{\mathrm{adj}}=3.3,95 \% \mathrm{CI}=3.0-3.6\right)$, and repeat tester after suspected failure $\left(\mathrm{OR}_{\mathrm{adj}}=6.3,95 \% \mathrm{CI}=5.5-\right.$ $7.2)$, being a child aged $0-4$ years $\left(\mathrm{OR}_{\mathrm{adj}}=5.3\right.$, $95 \% \mathrm{CI}=4.6-6.1)$, being an adolescent aged $15-19$ years $\left(\mathrm{OR}_{\mathrm{adj}}=4.1,95 \% \mathrm{CI}=3.7-4.6\right)$, having reported adherence level $<85 \%\left(\mathrm{OR}_{\mathrm{adj}}=3.4,95 \% \mathrm{CI}=2.9 .4-3.9\right)$, and having active $\left(\mathrm{OR}_{\mathrm{adj}}=1.9,95 \% \mathrm{CI}=1.6-2.4\right)$ were significantly associated with increased odds of virological non-suppression. However, being on second/third line treatment $\left(\mathrm{OR}_{\mathrm{adj}}=0.86,95 \% \mathrm{CI}=0.78-0.95\right)$ reduced the odds of virological non-suppression (Table 3). 
Table 1 Socio-demographic and clinical characteristics of patients, August 2014-July 2015 ( $N=100,678$, routine monitoring, $n=94,766$, suspected treatment failures, $n=3492$ and second time testers, $n=1436$ )

\begin{tabular}{|c|c|c|c|c|}
\hline Variable & General-N(\%) & $\begin{array}{l}\text { Routine monitoring, } \\
n(\%)\end{array}$ & $\begin{array}{l}\text { Suspected treatment } \\
\text { failures, } n(\%)\end{array}$ & $\begin{array}{l}\text { Repeat testers after } \\
\text { suspected failure, } n(\%)\end{array}$ \\
\hline \multicolumn{5}{|l|}{ Age group } \\
\hline $0-4$ & $1763(2.0)$ & $1637(1.7)$ & $45(1.3)$ & $65(4.5)$ \\
\hline $5-9$ & $3983(4.0)$ & $3681(3.9)$ & $111(3.2)$ & 172(11.9) \\
\hline $10-14$ & $4231(4.0)$ & $3898(4.1)$ & 136(3.9) & 168(11.6) \\
\hline $15-19$ & $3085(3.0)$ & $2689(2.8)$ & $189(5.4)$ & $180(12.7)$ \\
\hline $20-24$ & $4781(5.0)$ & $4436(4.7)$ & $176(5.0)$ & 131(9.1) \\
\hline $25-29$ & $10,695(11.0)$ & $10,192(10.8)$ & $257(7.4)$ & $131(9.2)$ \\
\hline $30-34$ & $15,494(15.0)$ & $14,744(15.6)$ & $438(12.5)$ & 159(11.0) \\
\hline $35+$ & $56,646(56.0)$ & $53,489(56.4)$ & $2140(61.3)$ & $430(29.9)$ \\
\hline \multicolumn{5}{|l|}{ Sex } \\
\hline Male & $32,203(32.0)$ & $29,873(32.0)$ & $1539(45.0)$ & $515(36.0)$ \\
\hline Female & $67,097(68.0)$ & $63,598(68.0)$ & 1918(55.0) & $900(64.0)$ \\
\hline \multicolumn{5}{|l|}{ Duration on treatment } \\
\hline $0-2$ Years & $36,341(36.0)$ & $3,4610(36.6)$ & $1002(28.8)$ & 298(20.8) \\
\hline $3-5$ Years & $32,928(33.0)$ & $30,876(32.7)$ & $1240(35.7)$ & $548(38.3)$ \\
\hline 6-10 Years & $28,423(28.0)$ & $26,533(28.1)$ & $1110(31.9)$ & $534(37.3)$ \\
\hline$>10$ Years & $2726(3.0)$ & $2518(2.7)$ & 125(3.6) & $52(3.6)$ \\
\hline \multicolumn{5}{|l|}{ Indication for treatment initiation } \\
\hline TB infection & $4076(4.0)$ & $3721(4.0)$ & 129(3.9) & $127(9.4)$ \\
\hline Other & $1496(2.0)$ & $1392(2.0)$ & $72(2.2)$ & $24(1.8)$ \\
\hline Child under 15 & $9820(10.0)$ & $9550(10.0)$ & $83(2.5)$ & $59(4.4)$ \\
\hline PMTCT/Option B+ & $7712(8.0)$ & $7117(8.0)$ & $234(7.0)$ & $300(22.4)$ \\
\hline$C D 4<500$ & $74,401(76.0)$ & $70,116(76.0)$ & $2832(84.5)$ & $839(62.0)$ \\
\hline \multicolumn{5}{|l|}{ Report ARV adherence } \\
\hline$<85 \%$ & $1292(1.3)$ & $964(1.0)$ & $253(7.5)$ & $62(5.0)$ \\
\hline Fair 85-95\% & $10,065(10.4)$ & $8798(10.0)$ & $832(24.7)$ & $291(21.0)$ \\
\hline Good >95\% & $85,440(88.3)$ & $81,478(89.0)$ & $2278(67.7)$ & 1005(74.0) \\
\hline \multicolumn{5}{|l|}{ Treatment line } \\
\hline First line & $94,476(94.45)$ & $89,382(95.0)$ & $3177(92.2)$ & 1070(75.0) \\
\hline Second line & $5497(5.5)$ & $4815(5.0)$ & $264(7.7)$ & $354(25.0)$ \\
\hline Third line & $50(0.05)$ & $39(0.0)$ & $4(0.1)$ & $4(0.0)$ \\
\hline \multicolumn{5}{|l|}{ Pregnant } \\
\hline Yes & 2009(3.0) & $1950(2.0)$ & $27(1.0)$ & $33(2.4)$ \\
\hline \multicolumn{5}{|l|}{ Breast feeding } \\
\hline Yes & $4697(7.0)$ & $4647(5.0)$ & $52(2.0)$ & $35(3.0)$ \\
\hline \multicolumn{5}{|l|}{ Active TB } \\
\hline Yes & $668(1.0)$ & $575(0.6)$ & $77(2.3)$ & $15(1.1)$ \\
\hline \multicolumn{5}{|l|}{ Level of health facility } \\
\hline $\mathrm{HCll}+\mathrm{HCll}$ & $1,5404(15.0)$ & $14,757(16.0)$ & $376(11.0)$ & $85(6.0)$ \\
\hline HCIV + General hospital & $26,102(26.0)$ & $24,713(26.0)$ & $969(28.0)$ & 155(11.0) \\
\hline Specialized HIV cares services & $13,944(14.0)$ & $13,224(14.0)$ & $398(11.0)$ & $146(10.0)$ \\
\hline $\mathrm{RRH}+\mathrm{NRH}$ & $45,203(45.0)$ & $42,047(44.0)$ & $1747(50.0)$ & 1050(73.0) \\
\hline
\end{tabular}


Table 2 Proportion of HIV patients on ART with virological non-suppression, ( $N=100,678$, routine monitoring, $n=94,766$, suspected treatment failures, $n=3492$ and second time testers, $n=1436$ )

\begin{tabular}{|c|c|c|c|c|}
\hline \multirow[t]{2}{*}{ Variable } & \multicolumn{2}{|c|}{ Non-suppression status, $n(\%)$} & \multirow[b]{2}{*}{$\begin{array}{l}\text { Suspected treatment } \\
\text { failures }\end{array}$} & \multirow[b]{2}{*}{$\begin{array}{l}\text { Repeater testers after } \\
\text { suspected failure }\end{array}$} \\
\hline & General & Routine monitoring & & \\
\hline$\overline{\text { Overall }}$ & $10,805(11)$ & $8966(10)$ & 1018(29) & $716(50)$ \\
\hline \multicolumn{5}{|l|}{ Sex } \\
\hline Female & $6524(10)$ & $5437(9)$ & $592(31)$ & $427(47)$ \\
\hline Male & $4132(13)$ & $3402(11)$ & $416(27)$ & $278(54)$ \\
\hline \multicolumn{5}{|l|}{ Age category } \\
\hline $0-4$ & 507(29) & $444(27)$ & $22(49)$ & $34(52)$ \\
\hline $5-9$ & $916(23)$ & $754(21)$ & $55(50)$ & $104(60)$ \\
\hline $10-14$ & $960(23)$ & $765(20)$ & $83(61)$ & $105(63)$ \\
\hline $15-19$ & $837(27)$ & 614(23) & $102(54)$ & $118(66)$ \\
\hline $20-24$ & $746(16)$ & 595(13) & $81(46)$ & $65(50)$ \\
\hline $25-29$ & $1141(11)$ & $945(9)$ & $117(46)$ & $65(50)$ \\
\hline $30-34$ & $1579(10)$ & 1337(9) & 154(35) & $70(44)$ \\
\hline $35+$ & $4119(7)$ & $3512(7)$ & 404(19) & $155(36)$ \\
\hline \multicolumn{5}{|l|}{ Breast feeding } \\
\hline Yes & $297(6)$ & $262(6)$ & $22(42)$ & $14(40)$ \\
\hline No & $5964(10)$ & $8420(10)$ & $956(29)$ & $679(50)$ \\
\hline \multicolumn{5}{|l|}{ Pregnant } \\
\hline Yes & 153(8) & $128(7)$ & $13(48)$ & $14(42)$ \\
\hline No & 6113(10) & $8554(10)$ & $966(29)$ & $681(50)$ \\
\hline \multicolumn{5}{|l|}{ Active TB } \\
\hline Yes & $131(20)$ & $85(15)$ & $34(44)$ & $12(80)$ \\
\hline No & $10,236(11)$ & $8542(9)$ & $932(29)$ & $684(50)$ \\
\hline \multicolumn{5}{|l|}{ Treatment line } \\
\hline First & $9945(11)$ & $8351(9)$ & 925(29) & $582(54)$ \\
\hline Second & 736(13) & $531(11)$ & $75(28)$ & $128(36)$ \\
\hline Third & $11(22)$ & $4(10)$ & $3(75)$ & $3(75)$ \\
\hline \multicolumn{5}{|l|}{ Duration on treatment } \\
\hline $0-2$ Years & $3680(10)$ & 3198(9) & 291(29) & $133(45)$ \\
\hline $3-5$ Years & $3900(12)$ & $3226(10)$ & $386(31)$ & $264(48)$ \\
\hline 6-10 Years & 2928(10) & 2304(9) & $309(28)$ & $294(55)$ \\
\hline$>10$ Years & 257(9) & $210(8)$ & 24(19) & $22(42)$ \\
\hline \multicolumn{5}{|c|}{ Indication for treatment initiation } \\
\hline TB infection & 194(13) & 159(11) & $19(26)$ & $(16(67)$ \\
\hline Other & $604(15)$ & $466(13)$ & 49(38) & $77(61)$ \\
\hline Child under 15 & $1826(24)$ & $1508(21)$ & $135(58)$ & $170(57)$ \\
\hline PMTCT/Option B+ & $589(6)$ & $549(6)$ & $18(22)$ & $12(20)$ \\
\hline CD4 $<500$ & $7169(10)$ & $5955(9)$ & $750(26)$ & $401(48)$ \\
\hline \multicolumn{5}{|c|}{ Reported adherence level } \\
\hline$<85 \%$ & 453(35) & $324(34)$ & $85(34)$ & $38(61)$ \\
\hline $85-94 \%$ & 1659(17) & 1206(14) & 269(32) & 168(58) \\
\hline$>95 \%$ & $8145(10)$ & 6998(9) & $622(27)$ & $465(46)$ \\
\hline
\end{tabular}


Table 2 Proportion of HIV patients on ART with virological non-suppression, ( $N=100,678$, routine monitoring, $n=94,766$, suspected treatment failures, $n=3492$ and second time testers, $n=1436$ ) (Continued)

\begin{tabular}{|c|c|c|c|c|}
\hline \multicolumn{5}{|l|}{ Level of health facility } \\
\hline $\mathrm{HCll}+\mathrm{HCIII}$ & 1455(9) & 1295(9) & 104(28) & $36(42)$ \\
\hline HC IV + General hospital & 2293(9) & 1994(8) & $228(24)$ & $39(25)$ \\
\hline Specialized HIV care services & $1482(11)$ & $1242(9)$ & 148(37) & $83(57)$ \\
\hline $\mathrm{RRH}+\mathrm{NRH}$ & $5575(12)$ & $4435(11)$ & $538(31)$ & $558(53)$ \\
\hline
\end{tabular}

Denominator for pregnant/breastfeeding mothers was total females in the sample

$H C I I$ health centre two, $H C I I I$ health centre three, $H C I V$ health centre four, $R R H$ regional referral hospitals, $N R H$ national referral hospitals

\section{Factors associated with virological non-suppression: Sub-group analysis}

In a sub-group analysis of the factors associated with virological non-suppression among suspected treatment failures and repeat testers after suspected failure, we found that, among suspected treatment failures, breast feeding $\left(\mathrm{OR}_{\text {crude }}=1.8,95 \% \mathrm{CI}=1.0-3.2\right)$ and pregnancy $\left(\mathrm{OR}_{\text {crude }}=2.3,95 \% \mathrm{CI}=1.1-4.9\right)$ increased the odds of being virologically non-suppressed (at bivariate analysis level). On the other hand, among repeat testers after suspected failure, having active TB was associated with the highest odds of virological non-suppression $\left(\mathrm{OR}_{\mathrm{adj}}=7.0,95 \% \mathrm{CI}=1.4-32.1\right)$.

\section{Discussion}

In this descriptive cross-sectional study conducted to estimate the proportion of patients virologically nonsuppressed and to identify the factors associated with virological non-suppression, we found an overall proportion of non-suppression of $11 \%$. Amongst the 3 subpatient categories, patients on routine monitoring registered the lowest while repeat testers after suspected failure registered the highest proportion of nonsuppressed patients. Being a suspected treatment failure, repeat tester after suspected treatment failure, young age, poor adherence and having active TB increased the odds of virological non-suppression. Being on second/ third line treatment decreased the odds of virological non-suppression. Repeater testers after suspected failure with active TB registered the highest odds of nonsuppression compared to TB patients amongst other sub-categories.

Although our study reveals the overall proportion of non-suppressed patients being relatively low, we observe sub-groups such as children and adolescents, patients with adherence level $<85 \%$, patients with active TB, and repeat testers after suspected failure having relatively higher virological non-suppression levels. This calls for $\mathrm{MOH}$ to enhance efforts in the identified sub-groups to improve virological suppression.

Our findings show that repeat testers after suspected failure registered the highest non-suppression. Although the Uganda viral load monitoring guidelines recommend enhanced adherence counseling and support for patients whose first VL result is beyond the threshold, it is not clear whether the health care system is giving enough attention to these patients. The Uganda guidelines recommend use of text messages for adherence fostering. Other countries like Swaziland have developed and implemented targeted adherence support tools which recommend more frequent clinic reviews (1-monthly drug pick-ups from 3-monthly pick-ups), stepped-up adherence counseling (3 sessions) and education on the value for VL testing among other interventions. However, despite the use of a standard tool in Swaziland, there was no difference in the non-suppression rate amongst the re-testers which the authors associated with weaknesses in the counseling training and supervision [6]. Although WHO recommends adherence interventions for patients with detectable VL, no specification was given on the exact interventions to be undertaken [20]. Therefore, designing more efficient and effective follow up mechanisms for such patients is crucial. Further, it is critical to identify and answer key quality of care questions, such as: a) what happens when a VL result is received at a health facility?, b) do health care workers and patients understand the meaning and implication of different VL results?, c) are patients whose VL result is beyond the threshold given priority?, and d) are there any quality improvement interventions for such patients?

An elevated VL indicates poor adherence or resistance [21-25]. The current Uganda Ministry of Health viral load monitoring algorithm requires confirmatory testing after 6 months in the event of an elevated initial test [19]. This may lead to unnecessary delay in treatment switch for patients harboring resistance. Delaying ART switch for patients with resistance increases the risk of sexual transmission of ART-resistant strains [26-28], as well as the likelihood of subsequent failure on secondline therapy [21-24, 29] [30-32]. Therefore, the Ministry of Health should consider adopting resistance testing for persons with viral loads beyond the threshold or elevated viral loads. This will facilitate early identification of resistance and subsequent regimen switch.

We found that children and young adolescents were significantly more likely to be non-suppressed compared 
Table 3 Factors associated with virological non-suppression among HIV patients on ART, August 2014-July 2015, ( $N=100,678)$

\begin{tabular}{|c|c|c|c|c|}
\hline$\underline{\text { Variable }}$ & Not suppressed (\%) & Suppressed (\%) & $\mathrm{OR}_{\text {crude }}(95 \% \mathrm{Cl})$ & $\mathrm{OR}_{\mathrm{adj}}(95 \% \mathrm{Cl})^{\mathrm{a}}$ \\
\hline \multicolumn{5}{|l|}{ Reason for testing } \\
\hline Routine testing & $8966(84)$ & 8966(96) & 1.0 & 1.0 \\
\hline Suspected treatment failure & 1018(10) & 2474(3.0) & $4.2(3.6-4.2)$ & $3.3(3.0-3.6)$ \\
\hline Repeat testers after suspected failure & $716(6)$ & $720(1.0)$ & $9.5(8.6-10)$ & $6.3(5.5-7.2)$ \\
\hline \multicolumn{5}{|l|}{ Age category } \\
\hline $35+$ & $4119(38)$ & $52,527(59)$ & 1.0 & 1.0 \\
\hline $34-30$ & 1579(15) & $13,915(16)$ & $1.4(1.4-1.5)$ & $1.6(1.5-1.7)$ \\
\hline $29-25$ & 1141(11) & $9554(11)$ & $1.5(1.4-1.6)$ & $1.9(1.7-2.0)$ \\
\hline $24-20$ & $746(7)$ & $4035(5)$ & $2.4(2.2-2.6)$ & $2.7(2.5-3.0)$ \\
\hline $19-15$ & $837(8)$ & 2248(3) & $4.7(4.4-5.2)$ & $4.1(3.7-4.6)$ \\
\hline $14-10$ & $960(9)$ & $3271(4)$ & $3.7(3.5-4.1)$ & $3.3(2.9-3.7)$ \\
\hline $9-5$ & 916(9) & $3067(3)$ & $3.8(3.5-4.1)$ & $3.4(3.1-3.8)$ \\
\hline $4-0$ & $507(5)$ & $1256(1)$ & $5.1(4.6-5.7)$ & $5.3(4.6-6.1)$ \\
\hline \multicolumn{5}{|l|}{ Indication for treatment initiation } \\
\hline PMTCT/Option B+ & $589(6)$ & $9231(11)$ & 1.0 & 1.0 \\
\hline Child $<15$ Years & 1826(19) & $5886(7)$ & $4.9(4.4-5.6)$ & $2.1(1.9-2.4)$ \\
\hline TB infection & 194(2) & $1302(2)$ & 2.3(1.9-2.8) & $2.1(1.8-2.6)$ \\
\hline $\mathrm{CD} 4<500$ & $7169(73)$ & $67,232(80)$ & $1.7(1.5-1.8)$ & $2.0(1.8-2.2)$ \\
\hline \multicolumn{5}{|l|}{ ARV adherence } \\
\hline$>95 \%$ & $8145(79)$ & $77,295(89)$ & 1.0 & 1.0 \\
\hline $85-94 \%$ & $1659(17)$ & $8406(8)$ & $1.9(1.8-2.0)$ & $1.6(1.5-1.7)$ \\
\hline$<85 \%$ & $453(4)$ & $839(1)$ & $5.1(4.6-5.8)$ & $3.4(2.9-3.9)$ \\
\hline \multicolumn{5}{|l|}{ Treatment line } \\
\hline First line & $9945(93)$ & 8453(95) & 1.0 & 1.0 \\
\hline Second/Third line & $747(7)$ & $4800(5)$ & $1.3(1.3-1.4)$ & $0.86(0.78-0.95)$ \\
\hline \multicolumn{5}{|l|}{ Sex } \\
\hline Female & $6524(61)$ & $60,573(68)$ & 1.0 & 1.0 \\
\hline Male & 4132(39) & $28,071(32)$ & $1.4(1.3-1.4)$ & $1.2(1.1-1.3)$ \\
\hline \multicolumn{5}{|l|}{ Active TB } \\
\hline No & 1,0236(99) & $86,650(99)$ & 1.0 & 1.0 \\
\hline Yes & $131(1)$ & $537(1)$ & $2.1(1.7-2.5)$ & $1.9(1.6-2.4)$ \\
\hline \multicolumn{5}{|l|}{ Health Facility Level } \\
\hline $\mathrm{HCll}+\mathrm{HCIII}$ & 1455(13) & $13,949(16)$ & 1.0 & 1.0 \\
\hline HCIV + General hospital & 2293(21) & $23,809(27)$ & $0.92(0.86-0.99)$ & $0.89(0.82-0.97)$ \\
\hline Specialized HIV services & $1482(14)$ & $12,462(14)$ & $1.1(1.1-1.2)$ & $1.2(1.1-1.3)$ \\
\hline $\mathrm{RRH}+\mathrm{NRH}$ & $5575(52)$ & $39,628(44)$ & $1.3(1.3-1.4)$ & $1.0(0.96-1.1)$ \\
\hline \multicolumn{5}{|l|}{ Duration on treatment } \\
\hline $0-2$ Years & $3680(34)$ & $32,661(36)$ & 1.0 & 1.0 \\
\hline $3-5$ Years & $3900(36)$ & $29,028(32)$ & $1.2(1.1-1.3)$ & $1.3(1.2-1.4)$ \\
\hline $6-10$ Years & $2928(27)$ & 2549(28) & $1.0(0.97-1.1)$ & $1.1(1.1-1.2)$ \\
\hline$>10$ Years & $257(3)$ & $2469(4)$ & $0.92(0.81-1.1)$ & $0.91(0.78-1.1)$ \\
\hline \multicolumn{5}{|l|}{ Breast feeding } \\
\hline No & 5964(95) & $54,369(93)$ & 1.0 & \\
\hline Yes & $297(5)$ & $4400(8)$ & $0.61(0.54-0.69)$ & - \\
\hline
\end{tabular}


Table 3 Factors associated with virological non-suppression among HIV patients on ART, August 2014-July 2015, (N=100,678) (Continued)

\begin{tabular}{|c|c|c|c|c|}
\hline$\overline{\text { Pregna }}$ & & & & \\
\hline No & 6113(98) & $56,841(97)$ & & \\
\hline Yes & 153(2) & $1856(3)$ & $0.77(0.65-0.91)$ & - \\
\hline
\end{tabular}

to the rest of the age groups. Similarly, a recent study conducted in the US reported that older patients were more likely to achieve viral suppression [33]. Treatment for children and adolescents presents several challenges including the complexity in ARV dosing and the need to adjust doses as the children grow, which may be difficult especially for providers who are not skilled enough with pediatric care or too busy to track the suppression status. Treatment for children may also be affected by the type of caretakers for the child (i.e. parents vs. other caretakers), schooling environment (for those in schools), and transition to adolescent [34, 35]. Stigma, fear of disclosure, and stress may affect younger people more than their older counterparts [36-38]. Keeping young people in care by using social workers, peer supporters, and training on pediatric disclosure among health workers has been reported to contribute to improved ART adherence and hence better virological outcomes [39]. Alcohol, recreational drug use, and low socioeconomic status also contribute to non-adherence and hence virological failure among the young people $[40,41]$.

Our findings reveal that virological non-suppression is a common phenomenon even among people with good adherence, which highlights the need to ensure wide coverage and access to viral load testing services. This requires huge investments in viral load laboratory testing infrastructure and services, including point of care diagnostics especially in hard to reach areas. Further, a sufficient pool of trained providers is key to ensuring proper tracking, timely viral loads and quick action (including adherence support) based on the results.

HIV-associated TB is common among people on ART in Africa [42]. A number of cross-sectional studies have highlighted a link between incident TB and virological non-suppression [43-46]. However, the causality may not be clear given the inherit weaknesses of crosssectional studies. It is possible for virological failure to lead to incident TB.The risk of virological nonsuppression may also be increased by concurrent ART and TB treatment majorly due to impaired treatment adherence and pharmacokinetics drug interactions. Patients on ART with active TB should thus be prioritised for viral load monitoring and adherence support.
Strengthening; interventions that prevent incident TB during ART such as isoniazid prevent therapy and infection control at health facilities is crucial. Repeat testers after suspected failure with active $\mathrm{TB}$ registered the highest risk of non-suppression compared to TB patients amongst other sub-categories (for routine monitoring and suspected treatment failures). Repeat testers after suspected failure pending confirmation, are more likely not to adhere to their medicines and therefore being at highest risk for virological non-suppression compared to other sub-groups. In-addition, the $74 \%$ reported adherence level for these patients could partly explain this finding.

\section{Limitations}

The major limitation with our study was use of program data which had missing records. To enhance data quality, the laboratory is attempting to reduce this gap by making immediate phone calls to facilities where the samples are derived from. The cross-sectional study design may have misclassified transient viraemia as 'nonsuppressor' leading to higher proportions of patients with virological non-suppression. In-addition, the crosssectional study design, could not allow causality to be established. Clustering due to repeated samples in the same individual may have influenced the results in either direction. However, because of inconsistencies in the numbering of samples, we were not able to identify any repeat testers; and for this reason, we were not able to account for clustering effect in the analysis. In addition, although many studies have identified patient's CD4 count as one of the major factors associated with virological suppression, we did not assess it in our study. This was due to the fact that the data collection tool that was used to collect the data analyzed in this study did not have an option for patients' current CD4 count. The other limitation is that there could have been selection bias arising from the fact that the samples with complete records could have been obtained from individuals who were more motivated to seek viral load testing; or that patients who were tested could have been more likely to be non-suppressors. However, given that we used secondary data, it is very difficult to tell the extent to which selection bias exists or affects the interpretation of 
results. Our overall non-suppression level of 11\% (suppression of $89 \%$ ) suggests that Uganda is close to achieving the $90 \%$ viral suppression which is the UNAIDS target among HIV infected individuals on treatment. However, our study sample was only 100, 678 HIVpositive individuals versus the 750,896 individuals who were on active ART by the end of 2014 [18]. Thus, our findings may not be fully representative of the entire population on ART in Uganda.

The strength of this study was its large sample size and data on samples derived at the national level and thus provides a national outlook on the critical challenge of non-suppression amongst different populations receiving ART. This study identifies populations that require enhanced and targeted interventions to optimize $\mathrm{ART}$ and raises questions for additional research in this field.

\section{Conclusion}

Repeat testers after suspected failure registered the highest proportion of non-suppressed patients. Young age, poor adherence and having active TB increased the odds of virological non-suppression. Being on second/third line regimens was protective against non-suppression. We recommend close follow up and intensified targeted adherence support for suspected treatment failures, repeat testers after suspected failure, children and adolescents, and adherence to ART guidelines by ART clinics.

\section{Abbreviations \\ ART: Antiretroviral therapy; ARV: Antiretroviral; CD4: Cluster of differentiation 4; Cl: Confidence interval; CPHL: Central Public Health Laboratories; DBS: Dry blood spots; ePMTCT: Prevention of Mother-To-Child Transmission; HCll: Health center two; HCIII: Health center three; HCIV: Health center four; HIV: Human immunodeficiency virus; HIV/AIDS: Human immunodeficiency virus/Acquired immunodeficiency syndrome; $\mathrm{NRH}$ : National Referral Hospital; ORadj: Adjusted odds ratio; OR crude: Crude odds ratio; RNA: Ribonucleic acid; RRH: Regional Referral Hospital; TB: Tuberculosis; UNAIDS: Joint United Nations Programme on HIV/AIDS; VL: Viral load; WHO: World Health Organization}

\section{Acknowledgements}

The authors would like to thank Prossy Mbabazi, Joseph Kibirige, Faridah Namatovu, Miriam Nabukenya, Joyce Nambogo, Kushemererwe Grace and the entire staff of $C P H L$ for the routine $V L$ testing activities.

\section{Funding}

Routine collection of the data used in this study was supported by the Ministry of Health Uganda.

\section{Availability of data and materials}

The data that support the findings of this study are available from the Central Public Health Laboratories, Ministry of Health, Uganda but restrictions apply to the availability of these data and so are not publicly available. Data are however available from the corresponding author upon reasonable request and with permission of Central Public Health Laboratories, Ministry of Health, Uganda.

\section{Authors' contributions}

LB took lead in conceptualization of the study idea, protocol write up, data collection, compilation and conception of the manuscript idea and its write up. IS contributed to the data collection, compilation and conception of the manuscript idea and its write up, VN contributed to the conception of the manuscript idea and its write up, FN contributed to the conception of the manuscript idea and its write up, CK contributed to the conception of the manuscript idea and its write up, GP contributed to the conception of the manuscript idea and its write up, AAR contributed to the conception of the manuscript idea and its write up, JKBM contributed to the conception of the manuscript idea and its write up and revised the manuscript for substantial intellectual content, RKW contributed to the conceptualization of the idea, reviewed and revised the manuscript, and CK contributed to the data collection, compilation, conception of the manuscript idea and rigorous review of the manuscript. All authors read and approved the final manuscript.

\section{Competing interests}

The authors declare that they have no competing interests.

\section{Consent for publication}

Not applicable.

\section{Ethics approval and consent to participate}

We used program data collected for routine patient care at all health facilities in Uganda. These data were submitted to the CPHL which is mandated to conduct centralized viral load testing in Uganda. No personal identifiers were included. The data were not accessible by any other third parties other than the study team. Permission to use the data was sought from the Ugandan Ministry of Health under whose mandate CPHL falls.

\section{Disclaimer}

The lead author was supported by the US Centers for Disease Control and Prevention Cooperative Agreement number GH001353-01 through Makerere University School of Public Health to the Uganda Public Health Fellowship Program, Ministry of Health. Its contents are solely the responsibility of the authors and do not necessarily represent the official views of the US Centers for Disease Control and Prevention, the Agency for Toxic Substances and Disease Registry, the Department of Health and Human Services, Makerere University School of Public Health, or the Ministry of Health.

\section{Publisher's Note}

Springer Nature remains neutral with regard to jurisdictional claims in published maps and institutional affiliations.

\section{Author details}

${ }^{1}$ Uganda Public Health Fellowship Program - Field Epidemiology Track, Kampala, Uganda. ${ }^{2}$ Central Public Health Laboratories, Ministry of Health, Kampala, Uganda. ${ }^{3}$ Makerere University School of Public Health, Kampala, Uganda.

Received: 14 October 2016 Accepted: 28 April 2017

Published online: 03 May 2017

\section{References}

1. WHO. Antiretroviral therapy (ART) coverage among all age groups 2015 [cited 2017 20/03/2017]. Available from: http://www.who.int/gho/hiv/ epidemic_response/ART_text/en/.

2. WHO. Consolidated guidelines on the use of antiretroviral drugs for treating and preventing HIV infection, recommendations for a public health approach. 2013 [cited 2016 01/10/2016]. Available from: http://www.who. int/hiv/pub/arv/arv-2016/en/

3. WHO. World Health Organization. HIV drug resistance. 2006 [cited 2016 02/ 03/2016]. Available from: http://www.who.int/hiv/topics/drugresistance/en/.

4. WHO. Technical Brief on HIV Viral Load Technologies 2010 [cited 2015 20/ 10/2015]. Available from: http://www.who.int/hiv/topics/treatment/tech_ brief_20100601_en.pdf.

5. Huong DTM, Bannister W, Phong PT, Kirk O, Peters L. Factors associated with HIV-1 virological failure in an outpatient clinic for HIV-infected people in Haiphong, Vietnam. Int J STD AIDS. 2011;22(11):659-64.

6. Jobanputra K, Parker LA, Azih C, Okello V, Maphalala G, Kershberger B, et al. Factors associated with virological failure and suppression after enhanced adherence counselling, in children, adolescents and adults on antiretroviral therapy for HIV in Swaziland. PLoS One. 2015;10(2):-e0116144. 
7. d'Arminio Monforte A, Lepri AC, Rezza G, Pezzotti P, Antinori A, Phillips AN et al. Insights into the reasons for discontinuation of the first highly active antiretroviral therapy (HAART) regimen in a cohort of antiretroviral naive patients. I.CO.N.A. Study Group. Italian Cohort of Antiretroviral-Naive Patients. AIDS (London, England). 2000;14(5):499-507.

8. Mocroft A, Youle M, Moore A, Sabin CA, Madge S, Lepri AC, et al. Reasons for modification and discontinuation of antiretrovirals: results from a single treatment centre. AIDS (London, England). 2001;15(2):185-94.

9. Paredes R, Lalama CM, Ribaudo HJ, Schackman BR, Shikuma C, Giguel F, et al. Pre-existing minority drug-resistant HIV-1 variants, adherence, and risk of antiretroviral treatment failure. J Infect Dis. 2010;201(5):662-71.

10. AIDSInfor. Guidelines for the Use of Antiretroviral Agents in HIV-1-Infected Adults and Adolescents. Management of the Treatment-Experienced Patient. 2015.

11. UNAIDS. 90-90-90, An ambitious treatment target to help end the AIDS epidemic. 2014.

12. James H McMahon, Julian H Elliott, Silvia Bertagnolio, Kubiak R, Jordan MR. Viral suppression after 12 months of antiretroviral therapy in lowandnmiddle-income countries: a systematic review. Bull World Health Organ 2013;91:377-385

13. Mona R. Loutfy, Wei Wu, Michelle Letchumanan, Lise Bondy, Tony Antoniou, Shari Margolese, et al. Systematic Review of HIV Transmission between Heterosexual Serodiscordant Couples where the HIV-Positive Partner Is Fully Suppressed on Antiretroviral Therapy. PLoS One. 2013;8(12)(10.1371):e55747.

14. Duber HC, Roberts DA, Ikilezi G, Fullman N, Gasasira A, Gakidou E, et al. Evaluating facility-based antiretroviral therapy programme effectiveness: a pilot study comparing viral load suppression and retention rates. Tropical Med Int Health. 2016;21(6):750-8.

15. Billioux A, Nakigozi G, Newell K, Chang LW, Quinn TC, Gray RH, et al. Durable Suppression of HIV-1 after Virologic Monitoring-Based Antiretroviral Adherence Counseling in Rakai, Uganda. PLoS One. 2015; 10(5):e0127235

16. Uganda Bureau of Statistics. National Population and Housing Census 2014, Provision Results. 2014

17. Uganda. AIDS Indicator Survey (AIS). Ministry of Health. 2011.

18. UNAIDS. HIV and AIDS Uganda country progress report. 2014

19. Uganda $\mathrm{MoH}$. Addendum to the National Antiretroviral Treatment Guidelines. 2013

20. WHO. Interim technical update: Technical and operational considerations for implementing HIV viral load testing 2014 [cited 2015 03/06/2015]. Available from: http://apps.who.int/iris/bitstream/10665/128121/1/9789241507578_ eng.pdf.

21. Hosseinipour MC, van Oosterhout JJ, Weigel R, Phiri S, Kamwendo D, Parkin $\mathrm{N}$, et al. The public health approach to identify antiretroviral therapy failure: high-level nucleoside reverse transcriptase inhibitor resistance among Malawians failing first-line antiretroviral therapy. AIDS (London, England) 2009;23(9):1127-34.

22. Kumarasamy N, Madhavan V, Venkatesh KK, Saravanan S, Kantor R, Balakrishnan $\mathrm{P}$, et al. High frequency of clinically significant mutations after first-line generic highly active antiretroviral therapy failure: implications for second-line options in resource-limited settings. Clin Infect Dis. 2009;49(2): 306-9.

23. Mee P, Fielding KL, Charalambous S, Churchyard GJ, Grant AD. Evaluation of the WHO criteria for antiretroviral treatment failure among adults in South Africa. AIDS (London, England). 2008;22:1971-7.

24. Pujades-Rodriguez M, O'Brien D, Humblet P, Calmy A. Second-line antiretroviral therapy in resource-limited settings: the experience of Medecins Sans Frontieres. AIDS (London, England). 2008;22(11):1305-12.

25. Hosseinipour MC, Kumwenda JJ, Weigel R, Brown LB, Mzinganjira D, Mhango B, et al. Second-line treatment in the Malawi antiretroviral programme: high early mortality, but good outcomes in survivors, despite extensive drug resistance at baseline(). HIV Med. 2010;11(8):510-8.

26. de la Rosa R, Ruíz-Mateos E, Rubio A, Abad MA, Vallejo A, Rivero L, et al. Long-term virological outcome and resistance mutations at virological rebound in HIV-infected adults on protease inhibitor-sparing highly active antiretroviral therapy. J Antimicrob Chemother. 2004;53(1):95-101.

27. Ndembi N, Goodall RL, Dunn DT, McCormick A, Burke A, Lyagoba F, et al. Viral rebound and emergence of drug resistance in the absence of viral load testing: a randomized comparison between zidovudine-lamivudine plus Nevirapine and zidovudine-lamivudine plus Abacavir. J Infect Dis. 2010; 201(1):106-13.
28. Tang MW, Shafer RW. HIV-1 antiretroviral resistance: scientific principles and clinical applications. Drugs. 2012;72(9):e1-25.

29. Mee P, Fielding KL, Charalambous S, Churchyard GJ, Grant AD. Evaluation of the WHO criteria for antiretroviral treatment failure among adults in South Africa. AIDS (London, England). 2008;22(15):1971-7.

30. Gupta RK, Hill A, Sawyer AW. Virological monitoring and resistance to firstline highly active antiretroviral therapy in adults infected with HIV-1 treated under WHO guidelines: a systematic review and meta-analysis. Lancet Infect Dis. 2009;9:409-17.

31. Marconi VC, Sunpath H, Lu Z, Gordon M, Koranteng-Apeagyei K, Hampton J, et al. Prevalence of HIV-1 drug resistance after failure of a first highly active antiretroviral therapy regimen in KwaZulu Natal, South Africa. Clin Infect Dis. 2008:46(10):1589-97.

32. Reynolds SJ, Kityo C, Mbamanya F, Dewar R, Ssali F, Quinn TC, et al. Evolution of drug resistance after virological failure of a first-line highly active antiretroviral therapy regimen in Uganda. Antivir Ther. 2009;14(2): 293-7.

33. Yehia BR, Rebeiro P, Althoff KN, Agwu AL, Horberg MA, Samji H, et al. The Impact of Age on Retention in Care and Viral Suppression. J Acquir Immune Defic Syndr. 2015;68(4):413-9.

34. Watson DCFJ. Efficacy of and adherence to highly active antiretroviral therapy in children infected with human immunodeficiency virus type 1. Pediatr Infect Dis J. 1999;18(8):682-9.

35. Garvie PA, Wilkins ML. JC Y. Medication adherence in adolescents with behaviorally-acquired HIV: evidence for using a multimethod assessment protocol. J Adolesc Health. 2010:47(5):504-11.

36. Brown L, Macintyre K, Trujillo L. Interventions to reduce HIV/AIDS stigma: what have we learned? AIDS Educ Prev. 2003;15(1):49-69.

37. Vanable PA, Carey MP, Blair DC, Littlewood RA. Impact of HIV-related stigma on health behaviors and psychological adjustment among HIV-positive men and women. AIDS Behav. 2006;10(5):473-82

38. Katz IT, Ryu AE, Onuegbu AG, Psaros C, Weiser SD, Bangsberg DR, et al. Impact of HIV-related stigma on treatment adherence: systematic review and meta-synthesis. J Int AIDS Soc. 2013;16(3 Suppl 2):18640.

39. van Griensven J, De Naeyer L, Uwera J, Asiimwe A, Gazille C, Reid T. Success with antiretroviral treatment for children in Kigali, Rwanda: experience with health center/nurse-based care BMC Pediatr 2008:8:39.

40. Reisner SL, Mimiaga MJ, Skeer M, Perkovich B, Johnson CV, Safren SA. A review of HIV antiretroviral adherence and intervention studies among HIVinfected youth. Top HIV Med. 2009;17(1):14-25.

41. Peltzer K, Pengpid S. Socioeconomic Factors in Adherence to HIV Therapy in Low- and Middle-income Countries. J Health Popul Nutr. 2013;31(2):150-70.

42. Lawn SD, Myer L, Bekker LG, Wood R. Burden of tuberculosis in an antiretroviral treatment programme in sub-Saharan Africa: impact on treatment outcomes and implications for tuberculosis control. AIDS (London, England). 2006:20(12):1605-12.

43. Komati S, Shaw PA, Stubbs N, Mathibedi MJ, Malan L, Sangweni P, et al. Tuberculosis risk factors and mortality for HIV-infected persons receiving antiretroviral therapy in South Africa. AIDS (London, England). 2010;24(12): 1849-55.

44. El-Khatib Z, Ekstrom AM, Ledwaba J, Mohapi L, Laher F, Karstaedt A, et al. Viremia and drug resistance among HIV-1 patients on antiretroviral treatment: a cross-sectional study in Soweto, South Africa. AIDS (London, England). 2010;24(11):1679-87.

45. Ahoua L, Guenther G, Pinoges L, Anguzu P, Chaix M-L, Le Tiec C, et al. Risk factors for virological failure and subtherapeutic antiretroviral drug concentrations in HIV-positive adults treated in rural northwestern Uganda. BMC Infect Dis. 2009;9(1):81.

46. Gupta A, Wood R, Kaplan R, Bekker L-G, Lawn SD. Prevalent and Incident Tuberculosis Are Independent Risk Factors for Mortality among Patients Accessing Antiretroviral Therapy in South Africa. PLoS One. 2013:8(2):e55824. 